\title{
Salmonella spp. em carcaças, carne mecanicamente separada, lingüiças e cortes comerciais de frango
}

\author{
Salmonella spp. in carcasses, mechanically deboned meat, \\ sausages and chicken meat
}

Angela Cleusa de Fátima Banzatto de Carvalho ${ }^{1}$ Ana Lígia Lordello Cortez ${ }^{2}$

\begin{abstract}
Alimentos de origem animal representam papel fundamental na epidemiologia das salmoneloses humanas. Apesar dos avanços tecnológicos, a carne de frango ainda é passível de contaminação bacteriana, especialmente por microrganismos do gênero Salmonella, que podem encontrarse albergados no trato intestinal ou em outra parte do corpo das aves. O presente trabalho objetivou pesquisar a ocorrência de Salmonella em carne de frango e derivados procedentes da região Nordeste do Estado de São Paulo. Foram analisadas, através do método convencional de cultivo, 45 amostras de carcaças, 60 de carne mecanicamente separada (CMS), 25 de lingüiça de frango, 20 de peito, e 15 de coxa e sobre-coxa. Salmonella spp. foi encontrada em $13,3 \%$ (6/45) das carcaças, 25\% (15/60) das amostras de CMS, $16 \%$ (4/25) das lingüiças, 30\% (6/20) dos peitos e $13,3 \%(2 / 15)$ das coxas e sobre-coxas analisadas. Do total de 165 amostras analisadas, 33 (20\%) apresentaram contaminação por Salmonella estando, portanto, impróprias para o consumo conforme legislação brasileira.
\end{abstract}

Palavras-chave: carne mecanicamente separada, frango, Salmonella.

\section{ABSTRACT}

Food of animal origin represents an important role in the epidemiology of human salmonellosis. In spite of the technological improvement, the chicken meat is subjected to bacterial contamination, mainly by microorganisms of the genus Salmonella that can be found in the intestinal tract or elsewhere on the chicken body. The aim of this study was to investigate the occurrence of Salmonella in chicken meat and cuts from the Northeast region of São Paulo State, Brazil. By conventional cultivation microbiological methods, 45 samples of carcasses, 60 samples of mechanically deboned meat (MDM), 25 samples of chicken sausages, 20 samples of chest, and 15 samples of chicken leg and thigh. Salmonella was found in $13.3 \%$ (6/45) of the carcass, 25\% (15/60) of the MDM, $16 \%(4 / 25)$ of the sausages, $30 \%(6 / 20)$ of the chests and $13.3 \%(2 / 15)$ of the tight analysed. The results showed that 33 (20\%) out of 165 samples were contaminated by Salmonella. Therefore, these samples were inappropriate for consumption, according to the Brazilian legislation.

Key words: chicken, mechanically deboned meat, Salmonella.

Surtos de toxinfecção alimentar causados por Salmonella são conhecidos, envolvendo os mais variados tipos de alimentos, verificando-se, no entanto, que a carne de aves é a mais freqüentemente envolvida (LANDGRAF \& FRANCO, 1996). Relatos de salmonelose veiculada por ovos e carne de aves, principalmente pela Salmonella enteritidis, tem sido relatado nos Estados Unidos, Europa e Brasil (JAY, 2000; PINTO, 2000; PARESI et al., 1998).

A ocorrência e a quantidade de Salmonella presente na carne varia de acordo com as condições de manejo durante a criação e com os cuidados higiênicos nas operações de abate dos animais e

${ }^{1}$ Faculdade de Ciências Agrárias e Veterinárias (FCAV), Universidade Estadual Paulista (UNESP), Campus de Jaboticabal. Via de Acesso Prof. Paulo Donato Castelane s/n, 14.887-076, Jaboticabal, SP, Brasil. E-mail : abanzato@fcav.unesp.br.

${ }^{2}$ Pós-graduação em Medicina Veterinária, FCAV, UNESP, Câmpus de Jaboticabal, Jaboticabal, SP, Brasil. 
posterior manipulação das carcaças. Apesar dos avanços tecnológicos, a carne de frango ainda é passível de contaminação bacteriana, especialmente por microrganismos do gênero Salmonella que se encontram albergados no trato intestinal podendo contaminar as carcaças bem como outros produtos caso o processo de abate não seja realizado com cuidados higiênicos.

Levantamento em diferentes países tem mostrado que 30 a $50 \%$ das carcaças de frangos congelados ou refrigerados estão contaminados por Salmonella (SILVA, 1998; SILVA et al., 2004). No Brasil, há relatos de contaminação por Salmonella em frangos e seus derivados variando de 9,15 a 86,7\% (ALMEIDA et al., 2000; SÁ BARRETO \& RAMOS, 1999; BAU et al., 1999).

Desta maneira os alimentos de origem animal, principalmente a carne de frango, representam papel fundamental na epidemiologia das salmoneloses humanas, podendo tornar-se um problema potencial na determinação de quadros de infecção alimentar em seus consumidores.

O presente trabalho teve como objetivos detectar a presença de Salmonella em produtos de frango prontos para serem distribuídos no comércio e classificar as amostras processadas quanto à presença ou ausência de Salmonella spp. em 25g, com base nos padrões estabelecidos pela legislação brasileira (BRASIL, 2001).

As amostras analisadas foram procedentes de diferentes frigoríficos da região Noroeste do Estado de São Paulo - SP, durante o período de1998 a 2002, em pacotes fechados e prontos para serem distribuídos no comércio. As amostras foram assim representadas: 45 amostras de carcaças, 60 de carne mecanicamente separada (CMS), 25 de lingüiça de frango, 20 de peito e 15 de coxa e sobre-coxa, totalizando 165 amostras analisadas. As amostras foram transportadas ao laboratório para processamento em caixas isotérmicas com gelo.

De cada amostra, 25g foram homogeneizados com $225 \mathrm{~mL}$ de água peptonada $0,1 \%$ esterelizada e incubados por 18 a $24 \mathrm{~h} \mathrm{a} 42^{\circ} \mathrm{C}$. Alíquotas de $1 \mathrm{~mL}$ dessa cultura pré-enriquecida foram transferidas para dois tubos, contendo cada um $10 \mathrm{~mL}$ de caldo de enriquecimento seletivo, composto pelo caldo tetrationato e pelo caldo Rappaport Vassiliadis, e incubadas a $43^{\circ} \mathrm{C}$ por $24 \mathrm{~h}$. A partir desses caldos, uma alíquota de cada tubo foi semeada em ágar verdebrilhante vermelho-de-fenol-lactose-sacarose (BPLS) adicionado de $0,1 \mathrm{~mL}$ de solução de novobiocina a $4 \%$ para cada $100 \mathrm{~mL}$ de meio básico, e outra em ágar MacConkey e incubadas a $35^{\circ} \mathrm{C}$ por $24 \mathrm{~h}$. Do ágar BPLS selecionaram-se colônias incolores ou de cor rosada entre translúcida e ligeiramente opaca e cujo meio básico apresentava tom maravilha. Do ágar MacConkey, selecionaram-se as colônias incolores e com meio básico na cor palha. Ambas foram semeadas em ágar tríplice açúcar ferro (TSI) e ágar ferro lisina (LIA), com incubação a $37^{\circ} \mathrm{C}$ por $24 \mathrm{~h}$. As culturas com base ácida, produção de gás e bisel alcalino e com produção de $\mathrm{H}_{2} \mathrm{~S}$ foram adicionadas de $2 \mathrm{~mL}$ de solução salina a $0,85 \%$ e após foram homogeneizadas para teste de aglutinação com soros polivalentes contra os antígenos somáticos e flagelares de Salmonella spp. (BRASIL,1993).

Do total de 165 (100\%) amostras analisadas, 33 (20\%) apresentaram contaminação por Salmonella spp. ( Tabela 1). Quando se analisa em separado cada uma das amostras estudadas, observa-se que Salmonella spp. esteve presente em seis (13,3\%) das 45 amostras de carcaças, em 15 (25\%) das 60 amostras de CMS, em quatro (16\%) das 25 amostras de lingüiças, em seis (30\%) das 20 amostras de peitos e em duas $(13,3 \%)$ das 15 amostras de coxas e sobre-coxas analisadas (Tabela 1).

A presença de Salmonella spp. em carne de aves e seus derivados tem sido relatada em várias pesquisas. Na presente pesquisa $6(13,3 \%)$ das 45 amostras analisadas, não atenderam o padrão de ausência de Salmonella em $25 \mathrm{~g}$ do produto analisado, conforme estabelecido pela legislação, estando, portanto, este produto impróprio para o consumo. SILVA et al. (2004) relatam a presença deste microrganismo em 13 das 68 amostras analisadas, TESSARI et al. (2003) em 13 das 68 amostras pesquisadas e ALMEIDA FILHO et al. (2003) constatou 18 amostras contaminadas por Salmonella das 40 analisadas. Esses dados demonstram uma preocupação quanto aos critérios higiênicos sanitários adotados nas cadeias produtivas avícolas,

Tabela 1- Tipo de amostra, número e porcentagem de isolamento de Salmonella spp. em carcaça de aves e derivados, procedentes de frigoríficos da região Noroeste do Estado de São Paulo- SP, no período de 1998 a 2002.

\begin{tabular}{lcc}
\hline Tipo de Amostra & $\begin{array}{l}\mathrm{N}^{\circ} \\
\text { analisadas }\end{array}$ & $\begin{array}{l}\mathrm{N}^{\mathrm{a}} \\
\text { positivas }\end{array}$ \\
\hline Carcaça & 45 & $6(13,3 \%)$ \\
CMS $^{*}$ & 60 & $15(25,0 \%)$ \\
Lingüiça & 25 & $4(16,0 \%)$ \\
Peito & 20 & $6(30,0 \%)$ \\
Coxa e sobre-coxa & 15 & $2(13,3 \%)$ \\
Total & 165 & $33(20,0 \%)$ \\
\hline
\end{tabular}

*CMS - Carne Mecanicamente Separada 
principalmente pela relevância deste patógeno na saúde pública.

$\mathrm{Na}$ carne mecanicamente separada, constatou-se que 15 ( 25\%) das 60 amostras estavam contaminadas com Salmonella. Levando-se em consideração que esse produto geralmente é utilizado como matéria prima na composição de vários produtos cárneos, é de suma importância manter sua qualidade microbiológica, porém os dados observados na literatura comprovam que nem sempre este produto tem apresentado boa qualidade. CARVALHO et al. (2002) descreve a contaminação por Salmonella sp. em $8(16,0 \%)$ e $2(4,0 \%)$ das amostras de CMS recém obtida e congelada respectivamente. Já GARCIA (2002) constatou a presença em 21 (26,2\%) das amostras, enquanto HOFFMANN et al. (2002) não detectaram o microrganismo nas três amostras analisadas, descartando a possibilidade desta ser uma fonte de contaminação. A positividade dos resultados podem ser justificados pela introdução no abatedouro de aves já contaminadas, pelas deficiências em instalações e precárias condições de higiene durante o abate, como água, manipulação das carcaças, facilitando a proliferação destes microrganismos, refletindo desta maneira na contaminação da CMS.

A positividade de Salmonella encontrada nas lingüiças de frango foi de 4 (16,0\%) em 25 amostras, enquanto LÌRIO et al. (1998) detectaram $10 \%$ das lingüiças cruas contaminadas, não mencionando o número de amostras analisadas, e CORTEZ (2003) observou apenas uma amostra positiva $(4,7 \%)$ das 21 avaliadas. A grande manipulação do produto durante a preparação, aliada a exposição da carne a diversas fontes de contaminação ou ainda a procedência de lotes de aves já contaminados contribuem favoravelmente para a contaminação do produto final. Da mesma forma, os cortes de frango cuja manipulação também é considerável, a probabilidade de contaminação aumenta se a bactéria estiver presente na linha de abate. No presente trabalho, Salmonella spp. foi encontrada em $30 \%(6 / 20)$ das amostras de cortes de peito e 13,3\% (2/15) nas de coxas e sobrecoxas analisadas. GONÇALVES et al. (1998) detectaram a presença de Salmonella em 26,7 \% das amostras de coxa e peito analisados e SÁ BARRETO \& RAMOS (1999) em duas (14,2\%) das amostras de cortes congelados de frango.

A legislação brasileira (BRASIL, 2001) estabelece o padrão de ausência de Salmonella em $25 \mathrm{~g}$ de produto. Este trabalho verificou que $20 \%$ das amostras analisadas encontravam-se impróprias para o consumo humano.
Diante dos resultados obtidos, torna-se claro o risco potencial que esses alimentos podem representar para a saúde da população consumidora, não devendo, portanto, medir esforços para que medidas efetivas sejam tomadas nas indústrias e que as autoridades da vigilância sanitária possam atuar com maior fiscalização na busca da diminuição da Salmonella em aves.

\section{REFERÊNCIAS}

ALMEIDA, I.C. et al. Isolamento e identificação de Salmonella em carcaças de frango congelados e frescais, através de método rápido. Higiene Alimentar, v.14, n.70, p.5962, 2000.

ALMEIDA FILHO, E.S. et al. Pesquisa de Salmonella spp em carcaças de frango (Gallus Gallus), comercializadas em feira livre ou em supermercado no município de Cuiabá, MT, Brasil. Higiene Alimentar, v.17, n.110, p.74-79, 2003.

BAU, A.C. et al. Salmonella em produtos de frango e ovos de galinha comercializados em Pelotas - RS. Higiene Alimentar, v.13, n.60, p.26, 1999.

BRASIL. Agência Nacional de Vigilância Sanitária. Resolução no 12 , de 2 de janeiro de 2001. Regulamento técnico sobre os padrões microbiológicos para alimentos. 2001. Disponível em: http://www.anvisa.gov.br/Regis/resol/12oirac.num. Online. Acesso em 19/01/2002.

BRASIL. Ministério da Agricultura, do Abastecimento e da Reforma Agrária. Portaria no 100, de 10 de agosto de 1993. Diário Oficial da República Federativa do Brasil, Brasília, n.156, p.11950. Seção I, 1993.

CARVALHO, A.C.F.B. et al. Avaliação microbiológica da carne de ave mecanicamente separada (CAMS). Higiene Alimentar, v.16, n.98, p.91-100, 2002.

CORTEZ, A.L.L. Indicadores de qualidade higiênicosanitária em lingüiça frescal comercializada no município de Jaboticabal, SP. 2003. 42f. Dissertação (Mestrado em Medicina Veterinária Preventiva) - Faculdade de Ciências Agrárias e Veterinárias, Universidade Estadual Paulista, Jaboticabal.

GARCIA, T.C.L.F. Avaliação da qualidade microbiológica de carnes mecanicamente separadas de origem avícola obtidas por dois processos de produção. 2002. $66 \mathrm{f}$. Dissertação (Mestrado) - UNESP, Jaboticabal.

GONÇALVES, P.M.R. et al. Enumreação de enterococos e coliformes fecais, pesquisa de Salmonella e indicação preventiva de proteus em cortes e miúdos de frangos (Gallus domesticus) congelados. Higiene Alimentar, v.112, n.54, p.42-47, 1998.

HOFFMANN, F.L. et al. Microbiologia de carcaças e carne mecanicamente separada (CMS), obtidas em abatedouro de aves na região de São José do Rio Preto, SP. Higiene Alimentar, v.16, n.92/93, p.45-50, 2002.

JAY, J.M. Modern food microbiology. 6.ed. Maryland: Aspen, 2000. 679p. 
LANDGRAF, M.; FRANCO, B.D.G.M. Doenças microbianas de origem alimentar provocadas por enteropatógenos. Revista de Ciências Farmacêuticas, v.17, p.77-113, 1996.

LÍRIO, V.S. et al. Freqüência de 17 sorotipos de Salmonella isolados em alimentos. Higiene Alimentar, v.12, n.55, p.36-42, 1998.

PARESI, J.T.M. et al. Surtos de enfermidades transmitidas por alimentos causados por Salmonella enteritidis. Revista de Saúde Pública, v.32, p.477-483, 1998.

PINTO, P.S.A. Aspectos sanitários da salmonelose como uma zoonose. Higiene Alimentar, v.14, n.73, p.39-43, 2000 .
SÁ BARRETO, E.S.; RAMOS, S.M. Pesquisa de Salmonella em cortes congelados de frango comercializados no Município do Rio de Janeiro. Higiene Alimentar, v.13, n.61, p.53-54, 1999.

SILVA, J.A. Microrganismos patogênicos em carne de frangos. Higiene Alimentar, v.12, n.58, p.9-14, 1998.

SILVA, M.C.D. et al. Salmonella sp em ovos e carcaças de frangos "in natura” comercializadas em Maceió, AL. Higiene Alimentar, v.18, n.121, p.80-84, 2004.

TESSARI, E.N.C. et al. Prevalência de Salmonella enteritidis em carcaças de frango industrialmente processadas. Higiene Alimentar, v.17, n.107, p.52-55, 2003. 